КОШАРНАЯ Галина Борисовна - доктор социологических наук, профессор; заведующий кафедрой социологии и управления персоналом Пензенского государственного университета (440026, Россия, г. Пенза, ул. Чкалова, 68; k-galina1@yandex.ru)

ТАРХАНОВА Елена Сергеевна - кандидат социологических наук; доцент кафедры социологии и управления персоналом Пензенского государственного университета (440026, Россия, г. Пенза, ул. Чкалова, 68; helena_82@mail.ru)

ДАНИЛОВА Елена Александровна - кандидат социологических наук; доцент кафедры социологии и управления персоналом Пензенского государственного университета (440026, Россия, г. Пенза, ул. Чкалова, 68; danilovaea31@gmail.com)

\title{
ОСОБЕННОСТИ ЖЕНСКОЙ БЕЗРАБОТИЦЫ В СОВРЕМЕННОМ РОССИЙСКОМ ОБЩЕСТВЕ
}

Аннотация. В статье отмечается актуальность проблемы женской безработицы. Авторы выделяют и анализируют ее характерные особенности в условиях современной действительности на федеральном и региональном уровне (на примере Пензенской обл.). Одной из актуальных проблем видится диспропорция на рынке труда между женщинами и мужчинами. Проведенный анализ позволил определить факторы, влияющие на данную ситуацию, и проблему женской безработицы в целом.

Ключевые слова: безработица, дискриминация, женщины, женская безработица, неравенство, рынок труда

$\Pi$ роблема женской безработицы в российском обществе остается одной из актуальных на протяжении нескольких десятилетий как на федеральном уровне, так и в регионах. Во многом она обусловлена трансформационными процессами в обществе и социально-экономической нестабильностью, наблюдающейся на разных этапах развития страны. В современных условиях одной из причин являются также гендерные противоречия и меры дискриминационного характера со стороны работодателей при формально равных условиях: наблюдается разница в возможностях трудоустройства, карьерном росте, оплате труда, доступе к руководящим постам у мужчин и женщин. К сожалению, социальноправовые механизмы и социально-экономическое регулирование проблемы со стороны государства и общества не всегда работают на практике, оказывая различное влияние на положение женщин и мужчин в социально-трудовой сфере. Например, по данным Федеральной службы государственной статистики, уровень участия женщин в трудоспособном возрасте (16-54 года) в рабочей силе в 2017 г. составлял 78,6\%1.

Соответственно, в современном российском обществе в меняющихся социально-экономических условиях настоятельно требуется регулирование проблем занятости отдельных категорий граждан, в частности женщин.

На основе проведенного комплексного анализа статистических данных, материалов социологических исследований, научной и периодической литературы нами были выделены характерные особенности женской безработицы в современном российском обществе.

Одну из основных особенностей данной проблемы можно выделить, анализируя причины незанятости (потери работы) женщинами. По официальным данным, женщины остаются без работы чаще всего в результате сокращения штатов (ликвидации предприятия), а мужчины - по собственному желанию. Среди причин незанятости очень часто называются и другие причины уволь-

\footnotetext{
1 Женщины и мужчины России. 2018: статистический сборник. М.: Росстат. 2018. С. 93.
} 
нения. По мнению Г.А. Монусовой, «другие причины» - это «зачастую обстоятельства добровольно-принудительного характера: решение об увольнении принимается вроде бы добровольно, но под сильным давлением тех или иных факторов» [Монусова 2001: 115].

Федеральная служба государственной статистики представляет распределение безработных женщин и мужчин в возрасте 15-72 лет по причинам незанятости. Например, высокий показатель увольнений среди женщин в связи «с сокращением штатов, ликвидацией предприятия, прекращением собственного дела» наблюдался в 2013 г. - 60,8\%, тогда как у мужчин он составлял 39,2\%; по собственному желанию уволились $56,6 \%$ женщин и 43,4\% мужчин; другие обстоятельства незанятости приблизительно одинаковы - 51,3\% женщин и $48,7 \%$ мужчин ${ }^{1}$.

В 2017 г. показатели вышеперечисленных причин незанятости женщин и мужчин приблизительно одинаковые. Но в статистическом сборнике добавилась новая причина незанятости: «уволены в связи с окончанием срока действия срочного трудового договора, договора гражданско-правового характера» 2 , и здесь более высокий показатель у мужчин - 65\% против 35\% у женщин.

Анализируя результаты проведенного исследования в Пензенской обл. в 2018 г. $(N=148)$, можно выделить основные причины, по которым женщины не работают: уволились по собственному желанию $42 \%$ респондентов; потеряли работу в связи с ликвидацией предприятия (банкротства, закрытия) 16\% и сокращением кадров (в совокупности 12\%); по семейным обстоятельствам (вышли замуж, родили ребенка, поменяли место жительства) - $12 \%$; по соглашению сторон $-8 \%$, по истечении испытательного срока $-4 \%$, по другим причинам - 6\%. Среди «других причин» можно выделить варианты: «по состоянию здоровья (своему или членов семьи)», «не могу найти работу по специальности или интересную работу», «трудно совмещать работу и семейные обязанности, воспитание детей» и т.д. При этом женщины, уволившиеся по собственному желанию (42\% респондентов, $N=62$ ), на вопрос о причинах увольнения ответили следующее (см. рис. 1).
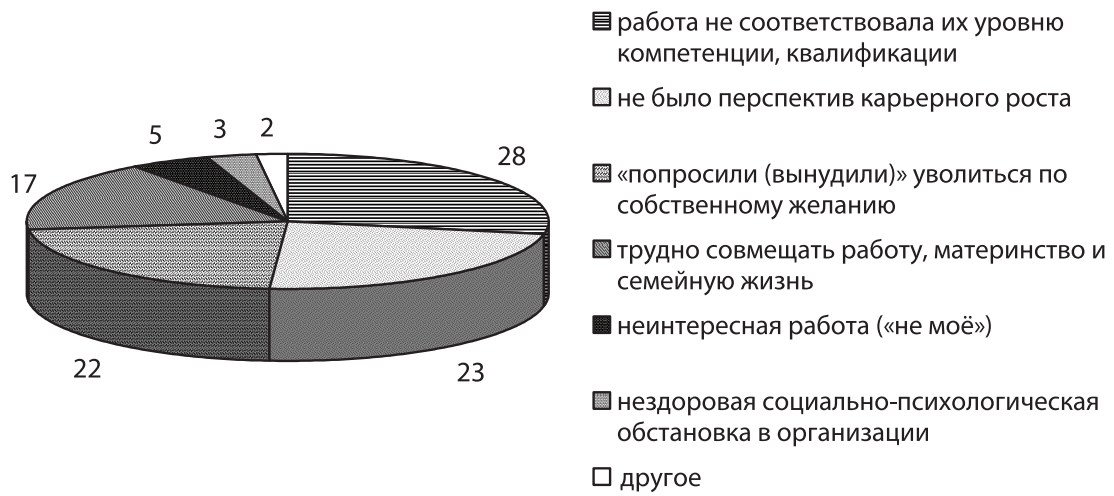

Рисунок 1. Распределение ответов на вопрос: «Почему Вы уволились с предыдущего места работы?», в \% от числа уволившихся по собственному желанию

\footnotetext{
1 Женщины и мужчины России. 2014. Приложение (в разрезе субъектов Российской Федерации): статистический сборник. М.: Росстат. 2014. С. 149.

2 Женщины и мужчины России. 2018: статистический сборник. М.: Росстат. 2018. С. 98.
} 
Можно предположить, что достаточно высокий показатель численности женщин, увольняющихся по собственному желанию, «по соглашению сторон», а также вариант ответа «другие причины» говорят о том, что их увольнение связано прежде всего с мерами дискриминационного характера со стороны работодателей, которые вынуждают женщин увольняться в связи с различными обстоятельствами.

Соответственно, исходя из полученных данных, можно предположить, что безработные женщины в Пензенской обл. имеют достаточно высокий уровень образования и квалификации и ориентированы на построение карьеры (в совокупности ответов более $50 \%$ ).

Следующая особенность женской безработицы связана со способами поиска работы. По статистике женщины чаще, чем мужчины, обращаются в службы занятости с целью поиска работы. По данным Росстата, в 2005 г. в службу занятости обратилось 28,3\% мужчин и 41,5\% женщин, в 2009 г. - 39,6\% мужчин и $60,4 \%$ женщин, в 2010 г. - 35,7\% мужчин и 41,4\% женщин ${ }^{1}$. Обращение в службу занятости с целью поиска работы был вторым по популярности. В июне 2013 г. в службу занятости обратились 28,6\% безработных мужчин и $32,4 \%$ безработных женщин; в 2014 г. - 31,1\% женщин и 25,2\% мужчин 2 ; в 2015 г. - 30,4\% женщин и 26,5\% мужчин; в 2016 г. - 30,6\% женщин и 25,7\% мужчин ${ }^{3}$. Однако с 2014 г. данный способ по популярности перемещается на 3-е место, а с 2016 г. - на 4-е.

В другом статистическом сборнике «Женщины и мужчины России» представлены следующие сведения. На протяжении нескольких лет (с 2013 по 2017 г.) $50 \%$ мужчин и женщин стабильно «обращаются в государственную службу занятости». Далее идут варианты, более популярные у мужчин: «обращение в коммерческую службу занятости» (в различные кадровые агентства) - в среднем $47 \%$ женщин и 52\% мужчин; «обращение в СМИ, Интернет» - также $47 \%$ женщин и $52 \%$ мужчин; «обращение к друзьям, родственникам, знакомым»$45 \%$ женщин и $54 \%$ мужчин и «непосредственное обращение к администрации/ работодателю» - 46\% женщин и $54 \%$ мужчин ${ }^{4}$. По последнему способу поиска работы показатель у женщин с годами постепенно увеличивается, а у мужчин снижается.

Следует отметить, что женщины, наряду с регистрацией в службе занятости, в поисках работы обращаются также к друзьям, родственникам, знакомым; в СМИ (объявления на телевидении, в газетах, журналах), к специализированным сайтам в сети Интернет и непосредственно к работодателю.

По данным Федеральной службы по труду и занятости РФ, женщины чаще, чем мужчины, обращаются в органы службы занятости населения по следующим причинам незанятости (см. рис. 2).

Результаты опроса в Пензенской обл. показали, что 52\% безработных женщин уже обратились в службу занятости, 58\% ищут работу с помощью друзей и родственников, $46 \%$ респондентов разместили резюме на специализированных сайтах; 24\% просматривают объявления в газетах и журналах, и только $11 \%$ обращаются напрямую к потенциальному работодателю и $8 \%$ - в кадровые агентства. Таким образом, респонденты используют одновременно несколько

\footnotetext{
1 Труд и занятость в России. 2011: статистический сборник. М.: Росстат. 2011. С. 132.

2 Занятость и безработица в 2012-2013 гг. - Официальный сайт Федеральной службы государственной статистики. Доступ: http://www.gks.ru/bgd/regl/b13_01/IssWWW.exe/Stg/d10/3-2.htm (проверено 03.06.2019).

3 Труд и занятость в России. 2017: статистический сборник. М.: Росстат. 2017. С. 85.

4 Женщины и мужчины России. 2018: статистический сборник. М.: Росстат. 2018. 241 с.; Женщины и мужчины России. 2014. Приложение (в разрезе субъектов Российской Федерации): статистический сборник. М.: Росстат. 2014. 217 с.; Женщины и мужчины России. 2016. Приложение (в разрезе субъектов Российской Федерации): статистический сборник. М.: Росстат. 2016. 208 с.
} 


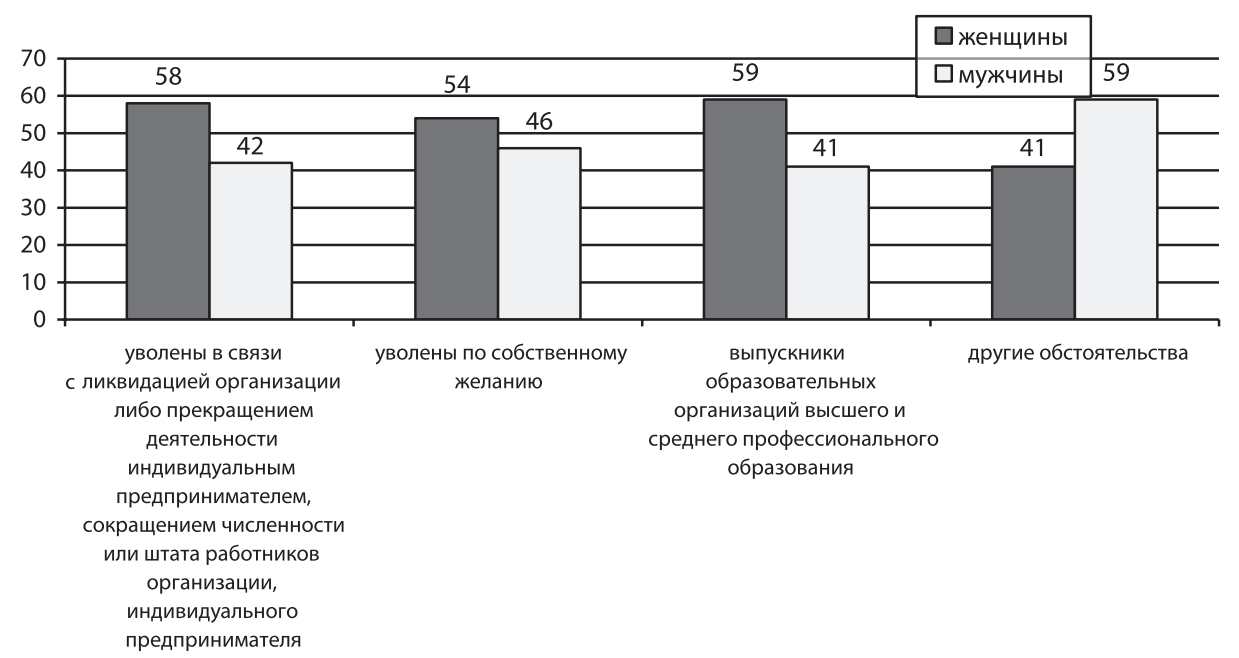

Примечание: ответы на вопрос предполагали многовариантность, поэтому сумма ответов больше $100 \%$.

Источник: составлено автором на основе анализа источника: Женщины и мужчины России. 2018: статистический сборник. М.: Росстат. 2018. 241 с.

Рисунок 2. Распределение зарегистрированных безработных женщин и мужчин по причинам незанятости (конец 2017 г.), в\%

способов поиска работы. Около половины респондентов (46\%) верят, что службы занятости помогут в трудоустройстве, и достаточно высоко оценивают их деятельность.

По данным Роструда, при содействии служб занятости нашли работу более половины зарегистрированных безработных женщин. На наш взгляд, данная характеристика обусловлена тем, что женщины лучше знакомы с порядком оформления статуса безработного, терпеливее и внимательнее относятся к процессу заполнения документов. А также женщины в большей степени готовы ждать и браться за любую предложенную работу. Кроме того, данная категория безработных имеет большую потребность в социальной защите, особенно беременные, женщины с детьми, женщины с ограниченными возможностями здоровья (инвалиды), пенсионеры, поэтому стремится получить различные социальные выплаты (или льготы).

Определенный процент женщин обращаются в службу занятости, чтобы сделать временный зарегистрированный и оплачиваемый «перерыв» в трудовой деятельности, который позволит им заняться семейными делами и/или дождаться более подходящей и интересной вакансии по уже имеющейся специальности [Романовский, Тарханова 2012: 106]. При этом в службах занятости имеется возможность пройти различные программы обучения и переподготовки, которые в настоящее время там представлены достаточно широко.

Мужчины же в связи с довольно низким размером пособия по безработице $(850-4900$ руб.) и в связи с непрестижностью регистрации в службе занятости предпочитают заниматься реальной временной подработкой и не отвлекаться на различные формальные регистрации.

Особенность женской безработицы также состоит в том, что зарегистрированные безработные женщины имеют более высокий уровень образования, чем мужчины. 
Результаты различных исследований свидетельствуют, что высшее образование значительно увеличивает шансы на трудоустройство и заработки работников во всех сферах деятельности - как у мужчин, так и у женщин. Чем выше уровень образования, тем ниже уровень безработицы.

В 2013 г. среди безработных женщин высшее профессиональное образование имели $21,1 \%, 32,1 \%$ женщин - среднее (полное) общее образование и только $0,6 \%$ не имеют основного общего образования. Эта тенденция сохранилась и в дальнейшем. В 2016 г. среди зарегистрированных безработных женщин 24,3\% имели высшее образование, 23,1\% - среднее профессиональное, 29,4\% - среднее общее [Кошарная 2018: 5]. В 2017 г. высшее образование имели 24,8\% женщин и $16,9 \%$ мужчин ${ }^{1}$. Распределение безработных женщин и мужчин в возрасте 15-72 лет по уровню образования в 2017 г. от общего числа официально зарегистрированных безработных более подробно представлено на рис. 3.

Эти показатели говорят о том, что в современных условиях даже с образованием трудно найти работу в силу разных обстоятельств. Например, порядка 80-90\% свободных рабочих мест рассчитаны на кадры рабочих профессий, а женщины, ищущие работу, в основном имеют другое образование и другую квалификацию и претендуют на вакансии специалистов, служащих, управляющих и т.П.

Также можно предположить, что этот показатель связан и с некоторыми дискриминационными мерами со стороны работодателей, которые «опасаются» очень «образованных женщин», разбирающихся в своих правах и претендующих на карьерный рост.

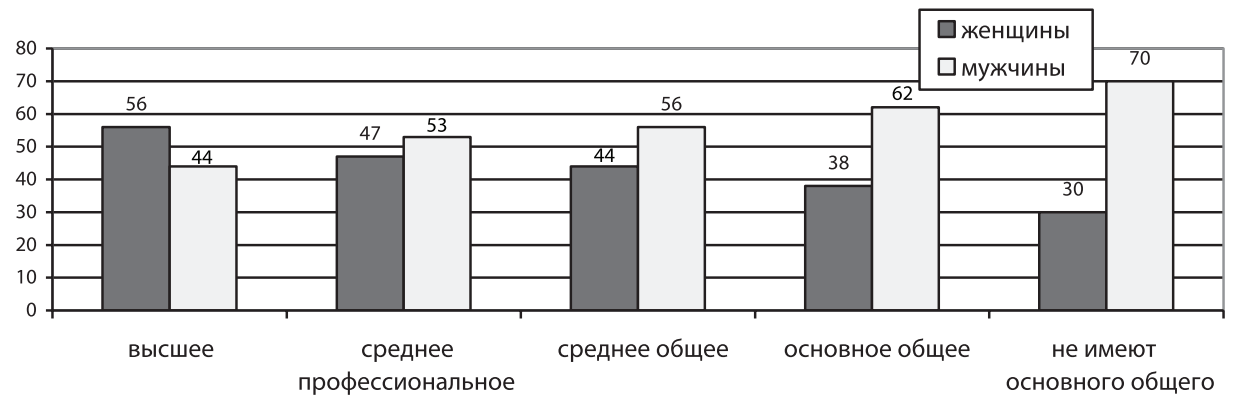

Источник: составлено автором на основе анализа источника: Женщины и мужчины России. 2018: статистический сборник. М.: Росстат. 2018. С. 156.

Рисунок 3. Распределение безработных женщин и мужчин в возрасте 1572 лет по уровню образования в 2017 г., в \%

49\% опрошенных безработных женщин в Пензенской обл. имеют высшее образование, $23 \%$ - только получают образование, еще не окончили обучение (учатся в вузе, колледже), 19\% имеют среднее профессиональное, $7 \%$ - среднее общее и только $2 \%$ - основное общее образование.

Уровень образования и уровень профессиональной квалификации безработных женщин тесно связан с опытом работы и сферой предыдущего места работы. Существуют расхождения в уровне квалификации выполняемых женщинами и мужчинами работ и видов деятельности. Статистические данные за

1 Женщины и мужчины России. 2018: статистический сборник. М.: Росстат. 2018. С. 156. 
2005-2016 гг. свидетельствуют, что в основном зарегистрированные безработные женщины имели опыт работы и квалификацию в сфере обслуживания, торговли, охраны граждан и собственности (в 2016 г. 24,1\% зарегистрированных безработных женщин) или являлись специалистами среднего и высшего уровня (в 2016 г. - 19,9\% женщин) $)^{1}$.

Около 75\% из числа опрошенных безработных женщин Пензенской обл. ответили, что имеют опыт работы в основном в сфере торговли, производства, образования, недвижимости, рекламы. На наш взгляд, это характеризует определенные профессионально-трудовые характеристики респондентов и дальнейшие перспективы профессионального развития.

Еще одной особенностью женской безработицы можно назвать продолжительность поиска работы. И.В. Костикова отмечала, что «доля женщин среди безработных, ищущих работу более года, на протяжении последних 10 лет всегда была выше, чем мужчин» [Введение в... 2015: 151]. Это особенно было характерно в кризисные периоды - в середине 1990-х и нулевых годах.

Согласно данным Росстата, средняя продолжительность поиска работы у безработных женщин в 2013 г. составила 7,7 месяца, в 2015 г. у женщин - 7,4 месяца, у мужчин - 7,1 месяца ${ }^{2}$, в 2016 г. - 7,8 месяца у женщин и 7,4 месяца у мужчин ${ }^{3}$. В 2017 г. средняя продолжительность поиска работы у женщин составляла 7,8 месяца, у мужчин - 7,5 месяца, а в сельской местности у женщин - 8,5 месяца, у мужчин $-8,3$ месяца 4 . Наибольший показатель длительности поиска работы наблюдается у женщин после 35 и старше 50 лет - более 8 месяцев. В Пензенской обл. по результатам опроса безработные женщины находились без работы в среднем 3-4 месяца.

По оценке специалистов и согласно статистическим данным чаще всего зарегистрированные безработные женщины либо находят работу за промежуток времени от 1 до 3 месяцев (в возрасте до 30 лет), либо числятся в качестве безработных более года и только после этого находят подходящую работу (как правило, уже старше 40 лет). Как видно, продолжительность поиска работы у мужчин и женщин постепенно выровнялась. Но на эти показатели следует обратить внимание в связи с изменениями пенсионного законодательства и, соответственно, разрабатывать более адресные программы трудоустройства и развивать механизм социального партнерства между федеральными, региональными властями и бизнес-сообществами в отношении женщин предпенсионного и пенсионного возрастов.

Анализ статистических данных показывает, что продолжительность поиска работы тесно связана с возрастом безработных. В последнее время в службу занятости чаще всего обращаются женщины в возрасте 30-40 лет и старше 50 лет. В 2016 г. средний возраст безработных составил 35,6 лет, в т.ч. безработных мужчин - 36 лет, безработных женщин - 35,2 года. Молодежь до 25 лет составляла среди безработных $23,9 \%$, лица в возрасте 50 лет и старше $-20,4 \% 5$. В 2017 г. средний возраст немного увеличился и составил 36,1 года для женщин и 36,5 года для мужчин 6 . Среди безработных в молодом возрасте (от 15 до 25 лет) доля женщин в 2018 г. составила 49,3\%, среди городских жителей -

\footnotetext{
1 Труд и занятость в России. 2017: статистический сборник. М.: Росстат. 2017. С. 83-84.

2 Женщины и мужчины России. 2016. Приложение (в разрезе субъектов Российской Федерации): статистический сборник. М.: Росстат. 2016. С. 144.

3 Труд и занятость в России. 2017: статистический сборник. М.: Росстат. 2017. С. 91.

4 Женщины и мужчины России. 2018: статистический сборник. М.: Росстат. 2018. С. 153-154.

5 Труд и занятость в России. 2017: статистический сборник. М.: Росстат. 2017. С. 77.

6 Женщины и мужчины России. 2018: статистический сборник. М.: Росстат. 2018. С. 148.
} 
$66,7 \%$, молодежи до 25 лет - 24,8\%, среди лиц, не имеющих опыта трудовой деятельности, $-26,3 \% 1$.

В связи с этим можно выделить еще одну особенность женской безработицы - это проблема трудоустройства девушек после окончания учебного заведения (до 25 лет). По статистике девушки сталкиваются с более серьезными проблемами при трудоустройстве, чем юноши. Стабильно высокий показатель безработных женщин отмечается в возрастной группе 20-29 лет: 36,1\% в 2016 г. и 34,6\% в 2017 г. ${ }^{2}$ Возможно, данный показатель обусловлен отсутствием опыта работы и тем, что более молодая часть женского населения (старше 20 лет) после получения образования ориентирована на создание семьи, дальнейшее получение образования и другие ценности.

Следующая особенность связана с семейным положением безработной женщины. В основном это замужние женщины - более 46\% в 2016-2017 гг. ${ }^{3}$ Можно предположить, что в современных нестабильных социально-экономических условиях, несмотря на то что женщина замужем, это не всегда означает, что муж полностью обеспечивает семью и женщина может позволить себе не работать. Как правило, она ищет работу, чтобы вносить определенный вклад в семейный бюджет. Однако в условиях высокой конкуренции и под влиянием других причин женщина испытывает проблемы с трудоустройством, поэтому с целью поиска работы, получения временного денежного содержания и возможности обучения (или переквалификации) вынуждена обращаться за помощью в службу занятости.

К следующей характерной особенности и одной из причин женской безработицы можно отнести дискриминацию, которая проявляется в возможностях трудоустройства, причинах увольнения, оплате труда, возможности карьерного роста и т.п. Например, согласно статистическим данным, за одинаковую с мужчиной работу женщина получает меньше «по всем укрупненным профессиональным группам работников, что составляет в среднем $64 \%$ от средней заработной платы мужчин» [Кошарная 2018: 5]. На наш взгляд, данный показатель также характеризует особенности положения женщин в трудовой сфере.

Региональный аспект этой проблемы может быть разным: чем выше уровень заработной платы в регионе, тем выше различия между заработной платой женщин и мужчин; и наоборот, в регионах с низкими доходами различия в заработной плате мужчин и женщин минимальны, а иногда заработки женщин даже выше.

Следует также отметить, что работодатели без энтузиазма принимают на работу беременных женщин и женщин, имеющих детей, т.к. считают их менее выгодными работниками из-за возможных перерывов в работе, вызванных деторождением и последующим уходом за детьми. По их мнению, данные категории женщин постоянно будут «отвлекаться от работы» по семейным обстоятельствам, состоянию здоровья членов семьи и к тому же терять квалификацию; им также придется предоставлять отгулы, различные социальные льготы и выплаты. Соответственно, женщины зачастую становятся первоочередными кандидатами на увольнение. Также работодатели могут увольнять или создавать условия для увольнения так называемых уязвимых категорий женщин: бере-

1 Занятость и безработица в Российской Федерации в октябре 2018 года. - Официальный сайт Федеральной службы государственной статистики. Доступ: https://nangs.org/analytics/rosstat-zanyatostibezrabotitsa-v-rossijskoj-federatsii-v-marte-2017-goda (проверено 03.06.2019).

2 Женщины и мужчины России. 2018: статистический сборник. М.: Росстат. 2018. С. 148.

3 Труд и занятость в России. 2017: статистический сборник. М.: Росстат. 2017. С. 81-82; Женщины и мужжчины России. 2018: статистический сборник. М.: Росстат. 2018. С. 152. 
менных, имеющих детей, детей-инвалидов, одиноких и многодетных матерей и т.П.

Например, интервьюирование потенциальных работодателей Пензенской обл. в 2018 г. $(N=20)$ показало, что только трое работодателей согласились трудоустроить беременную женщину, если уровень ее квалификации соответствует вакантной должности и если она очень нуждается в этой работе. Лишь 6 человек согласились взять на работу женщину с ребенком, при этом уточнив число детей и их возраст. Остальные 11 ответили, что им нужны молодые, активные, перспективные, адаптивные работники без обязательств.

По статистике уровень безработицы женщин в возрасте 20-49 лет, имеющих детей до 18 лет, в 2017 г. составил 5,3\%1, тогда как в Пензенской обл. среди опрошенных безработных женщин $60 \%$ имеют детей.

На наш взгляд, проанализированные показатели, на основе которых выделены особенности женской безработицы, во многом определяют качественные различия между безработными мужчинами и женщинами.

Таким образом, можно выделить несколько взаимосвязанных факторов, которые во многом носят дискриминационный характер и обусловливают диспропорцию между женщинами и мужчинами на рынке труда и проблему женской безработицы в целом. Во-первых, проявляется гендерное неравенство в доступе к определенным сферам экономической деятельности, которое сказывается при последующем трудоустройстве и оплате труда. Это объясняется вовсе не низким качеством женских трудовых ресурсов, уровнем образования и квалификации, а ограничениями для женщин возможностей выбора трудовой деятельности, которые в значительной степени обусловливаются ее семейным статусом. Поэтому для многих работодателей женская рабочая сила представляет меньший интерес из-за возможных декретных отпусков, больничных по уходу за детьми и другими членами семьи (иждивенцами). Во-вторых, потенциальные работодатели считают, что женщины могут утрачивать профессиональные знания и навыки в силу различных перерывов в работе. В-третьих, женщинам разных возрастных категорий при трудоустройстве могут предъявляться дополнительные (не всегда законные) требования и условия, не связанные с профессиональными качествами (например, не выходить замуж, не уходить в декрет или предлагают работу без оформления и т.п.).

На наш взгляд, на сегодняшний день женская безработица обусловлена не столько структурной перестройкой экономики и трансформационными процессами, происходящими в обществе, сколько проблемой дискриминации, существующей в обществе и в сфере труда, которая обостряется в условиях социально-экономической нестабильности и может принимать разные формы.

С учетом сказанного выше можно сделать вывод, что проблема женской безработицы все еще актуальна и требует более детального решения и проработки. Необходимо совершенствовать социальные механизмы по предупреждению и профилактике безработицы среди женщин, содействию в трудоустройстве женщинам с детьми и адаптации их на рынке труда в меняющихся социально-экономических условиях.

\section{Список литературы}

Введение в гендерные исследования (под ред. И.В. Костиковой). 2015. М.: Аспект Пресс. 235 c.

\footnotetext{
1 Женщины и мужчины России. 2018: статистический сборник. М.: Росстат. 2018. С. 106.
} 
Кошарная Г.Б. 2018. Гендерные различия в оплате на российском рынке труда. - Социокультурные факторы консолидации современного российского общества: сборник статей II Международной научно-практической конференции. Пенза: Приволжский Дом знаний. С. 3-6.

Монусова Г.А. 2001. Незанятость в России: вынужденная или добровольная. Вопросы экономики. № 9. С. 113-129.

Романовский Г.Б., Тарханова Е.С. 2012. Гендерные аспекты безработицы на региональном рынке труда - Известия высших учебных заведений. Поволжский регион. Общественные науки. № 3(23). С. 103-109.

KOSHARNAYA Galina Borisovna, Dr.Sci. (Soc.), Professor; Head of the Chair of Sociology and Personnel Management, Penza State University (68Chkalova St, Penza, Russia, 440026; k-galina1@yandex.ru)

TARKHANOVA Elena Sergeevna, Cand.Sci. (Soc.), Associate Professor of the Chair of Sociology and Personnel Management, Penza State University (68Chkalova St, Penza, Russia, 440026; helena_82@mail.ru)

DANILOVA Elena Aleksandrovna, Cand.Sci. (Soc.), Associate Professor of the Chair of Sociology and Personnel Management, Penza State University (68Chkalova St, Penza, Russia, 440026; danilovaea31@gmail.com)

\title{
FEATURES OF FEMALE UNEMPLOYMENT IN MODERN RUSSIAN SOCIETY
}

\begin{abstract}
The article notes the relevance of the problem of female unemployment, and highlights and analyzes its characteristic features in the conditions of modern reality at the federal and regional level (on the example of the Penza Region). One of the current problems is the disproportion in the labor market between women and men, and the analysis carried out had made it possible to identify the factors affecting this situation and the problem of female unemployment in general.
\end{abstract}

Keywords: unemployment, discrimination, women, female unemployment, inequality, labor market 